Ethiopian Journal of Environmental Studies \& Management 7(2): 124 - 133, 2014.

ISSN:1998-0507

doi: http://dx.doi.org/10.4314/ejesm.v7i2.3

Submitted: October 8, 2013

Accepted: February 17, 2014

\title{
EFFECT OF ELEPHANT BROWSING ON SELECTED SPECIES OF ACACIA ALONG THE GREAT RUAHA RIVER IN RUAHA NATIONAL PARK, TANZANIA
}

\author{
*NDIBALEMA, V.G., ${ }^{1}$ QOLLI, S.N. ${ }^{2}$ AND MAGANGA, S.L.S. ${ }^{1}$ \\ ${ }^{1}$ Department of Wildlife Management, Sokoine University of Agriculture, \\ P.O. Box 3073, Morogoro, Tanzania \\ ${ }^{2}$ Tanzania National Parks, P.O. Box 3034, Arusha, Tanzania.
}

\begin{abstract}
Elephant damage was assessed in 1,007 Acacia trees and responses between Acacia tortilis and A. kirkii in Ruaha National park were compared in 30 transects randomly placed in $38.8 \mathrm{~km}^{2}$ on the northern bank of Great Ruaha River (GRR) basing on six browsing categories and four debarking classes. There was no significant difference in browsing $\left(F_{1,10}=0.6, p>0.05\right)$ and debarking $\left(F_{1,6}=0.16, p>0.05\right)$ between $A$. kirkii and $A$. tortilis. Trees were classified into three height and twelve diameter classes. About 3613 trees $<1 \mathrm{~m}$ in height represented response in addition to coppices. The difference between the two species was observed only in regeneration potential $\left(F_{1,58}=41.4, p<0.05\right)$. In addition, low regeneration potential, severely browsed trees and restricted distribution made A. kirkii more vulnerable to elephant feeding compared to A. tortilis. The high A. tortilis regeneration potential suggests that the study area could become an Acacia bushland or woodland if fire is controlled. Further studies need to investigate, the suppressed regeneration of Acacia trees at Msembe, variations in vegetation utilization along the GRR and effects of fire and small browsers on Acacia species including monitoring of vegetation and animal trends.
\end{abstract}

Key words: Elephants, Acacia, Tree damage, Regeneration, Ruaha River

\section{Introduction}

The African elephant Loxodonta africana Blumenbach, being the largest terrestrial mammal, usually causes damage when feeding on trees (Nahonyo, 1996). Species affected most by elephant feeding include Adansonia digitata, Faidherbia albida and Commiphora ugogoensis (Barnes, 1985), Acacia tortilis (Mwalyosi, 1990), Colophospermum mopane (Lewis, 1991), Acacia xanthophloea (Kabigumila 1993), Acacia seyal, Sclerocarya birrea (Gadd, 2002) and Acacia elatior (Ihwagi et al., 2009).

Unlike other herbivores, elephants are adapted to use a wide range of plant species and various parts of these plants (Kerley et al., 2008). Feeding adaptations include use of the trunk, the high shoulder height, bipedal stance, use of tusks to strip bark off trees and gouge in soft stemmed trees or dig some woody and succulent species (Barnes 1982). Effects include debarking, breaking, felling, pushing over or uprooting young trees and seedlings during browsing, or when young bulls engage in social displays (Smallie and O'Connor, 2000), thereby reducing tree species diversity, mortality and undersized growth (Chira and Kinyamario, 2009). Tree damages tend to

*Corresponding Author: Ndibalema, V.G.

Email: ndibalema@suanet.ac.tz increase with elephants densities (Wahungu, 2011) in small isolated protected areas where corridors and dispersal areas are blocked by human settlements and other activities including agriculture (Ngene et al., 2009; Hema et al., 2010). Likewise, elephants tend to open closed woodland thereby increasing accessibility to resources and seed dispersal (Blake et al., 2009; Majid et al., 2010).

Most Acacia trees are nutritious hence browsed intensively by many herbivores than other tree species (Fornara and du Toit, 2007). This may cause decreased reproduction and recruitment (Young and Augustine, 2009) and in response many trees develop chemical and physical defenses including growth responses. Growth response includes massive compensations or change in plant phenology that reduce impact of herbivory. Physical defense mechanisms aim at reducing accessibility of leaves by increasing spine length and densities and reduction in leave size. Thorns or spines/ prickles defend Acacia trees from consistent browsing pressure from giraffe, impala, gerenuk and elephant (Dharani, 2006). Acacia drepanolobium form symbiotic association by developing swollen galls in which aggressive ants Crematigaster mimosae 
and C. nigriceps colonies restrain (Dino, 2010). The symbiotic ants deter large herbivores from browsing through attacking and causing irritation on their muzzles during browsing.

Responses to elephant browsing in this study refer to coppicing (re-growth of shoots) and regeneration. The word browse included breaking of branches and bole (Okula and Sise, 1986). This study therefore gives an insight on effects of elephants browsing on Acacia species and their response in the study area. Understanding elephant browsing effects and responses of Acacia species aim at promoting conservation understanding and habitat management to decision makers in protected areas.

\section{Material and Methods \\ Description of Study Area}

RNP is situated in the south-central Tanzania between $33^{\circ} 49^{\prime} \mathrm{E}$ and $53^{\circ} 24^{\prime} \mathrm{E}$ and $6^{0} 52^{\prime} \mathrm{S}$ and $7^{0} 57^{\prime} \mathrm{S}$ (Figure 1 ) and covers about $19,540 \mathrm{~km}^{2}$ with the altitude ranging from 750 to $1,863 \mathrm{~m}$ asl (TANAPA, 2008). The rainfall is unimodal with an average of $650 \mathrm{~mm}$ p.a, which increases with altitude towards Isonkavyola plateau (Bjørstad, 1976). There is a long dry season from May to November and mean annual temperature at Msembe is $24^{\circ} \mathrm{C}$.

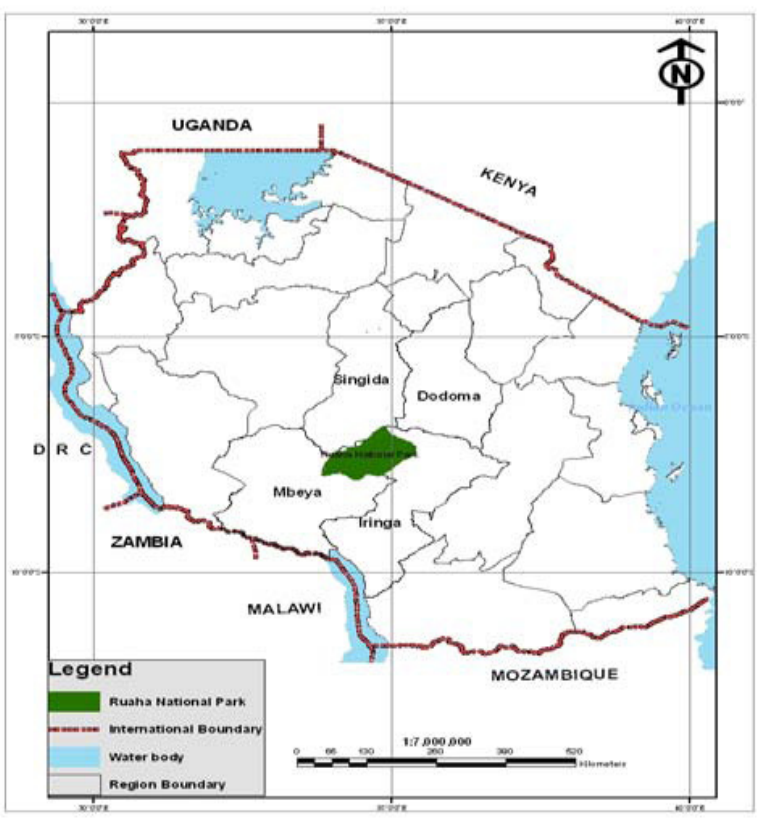

Figure 1: Location of RNP (Source: TANAPA 2008)

The park has four woody vegetation zones including; Acacia, Miombo (Brachystegia), Drypetes and Combretum. The area along the GRR supports a high concentration of animals, including elephants during the dry season. Comparatively, Acacia trees contain high crude protein levels than many other trees and are an important source of food for elephants in the area when most of the remaining trees species have shed leaves.

\section{Sampling and Data Collection}

Belt transects were divided into twenty $50 \mathrm{~m}$ x $20 \mathrm{~m}$ plots (White and Edwards, 2000). Transects were randomly located perpendicular to the northern bank of the GRR (Figure 2) spaced between 1,200-1,600m using random numbers. A $50 \mathrm{~m}$ line was established using a predetermined $50 \mathrm{~m}$ string with knots extending $10 \mathrm{~m}$ on each side. The ends of the $20 \mathrm{~m}$ string were flagged before moving them to a $50 \mathrm{~m}$ mark for a $50 \mathrm{~m} \times 20 \mathrm{~m}$ plot. This formed transect width of the first and subsequent plots. After collecting data, a $50 \mathrm{~m}$ string was moved with new starting point to another $50 \mathrm{~m}$ point to demarcate other plots. This procedure was repeated until the $1,000 \mathrm{~m}$ transect was complete. The direction of transect was maintained using GPS (Garmin Etrex). Coordinates were recorded at the beginning and end of each line using GPS.

The sampling intensity of $1.5 \%$ was used to calculate the sample size. Thus, sample size (n) for the study area (A) and $0.02 \mathrm{~km}^{2}$ sampled area (a) with $1.5 \%$ sampling intensity (SI) was $38.8 \mathrm{~km}^{2} \times 0.0125 / 0.02 \mathrm{~km}^{2}=29.91$ plots $(=30$ belt transects/plots). The study area size $\left(38.8 \mathrm{~km}^{2}\right)$ was determined using GIS software. In each transect, Acacia tree species were identified with a help from an experienced field assistant. Unidentified species were collected for further identification (Dharani, 2006). Four debarking classes; $\left(\mathrm{g}_{0}\right)$ stem not debarked, $\left(\mathrm{g}_{1}\right)$ $<1 / 2$ stem circumference debarked, $\left(g_{2}\right)_{1 / 2-3 / 4}$ stem circumference debarked and $\left(\mathrm{g}_{3}\right)$ stem completely debarked and six browsing categories; (a) not/slightly browsed (b) 1/4 tree crown browsed (c) $1 / 2$ tree crown browsed (d) $3 / 4$ tree crown browsed (e) whole crown browsed, and (f) tree uprooted (Okula and Sise 1986) were adopted. The tree crown was divided into four quarters and the portion damaged in each quarter was visually estimated and then added up to obtain the total damage of a given tree.

Diameter at breast height (DBH) and tree heights were measured using Suunto hypsometer, graduated stick and tap measure. Trees were later grouped following VeseyFitzgerald, (1973) and Okula and Sise, (1986) classes; (a) young trees $<1 \mathrm{~m}$ height were classified as regeneration potential, (b) trees between $1-3 \mathrm{~m}$ as recruitment potential (category that was in shrub layer and contributes to browse for elephant and other 
browsers) and (c) trees $>3 \mathrm{~m}$ as mature trees. DBH was measured for all Acacia trees at $130 \mathrm{~cm}$ from ground level using a caliper. The diameter for each multi-stemmed trees forking below $130 \mathrm{~cm}$ was measured and recorded separately and later grouped into 12 diameter classes. All Acacia trees with coppices and trees
$<1 \mathrm{~m}$ in height were recorded to indicate response from damage. Trees that appeared to have been killed due to elephant browsing and/or debarking were enumerated to determine relationship between tree killed and regeneration potential.

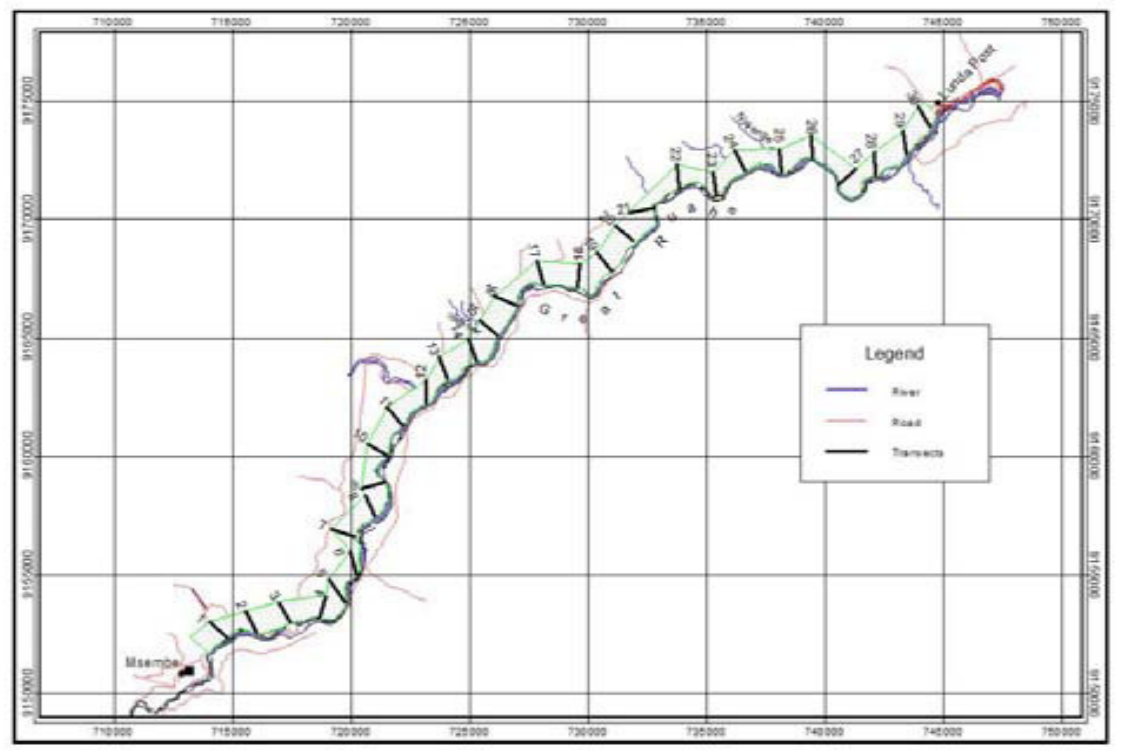

Figure 2: Location of transects in the study area (Source: Mapping and Survey Division 1972)

\section{Data Analysis}

Sampled Acacia trees were enumerated but Acacia tortilis and A. kirkii were only selected for comparison basing on their densities and distributions. Damages were tabulated accordingly and differences in mean counts between damage categories were tested (ANOVA and Microsoft-excel). Densities of Acacia trees were calculated as number of trees per ha for each of the two dominant Acacia species in all sub-plots across the 30 belt transects/plots. Variations in densities were tested using linear regression and basal area for each sampled Acacia tree was computed using the formula; $\mathrm{g}=\pi / 4 * \mathrm{~d}^{2}$ (Philip, 1994). Where; $\mathrm{d}$ $=$ diameter, $\mathrm{g}=$ basal $/$ cross-sectional area estimated at breast height $\left(\mathrm{m}^{2}\right)$ and $\pi=$ pie.

The basal area for multi-stemmed tree was computed separately. Average diameters for multi-stemmed trees were computed for diameter classification. Lastly, diameters were categorized into twelve classes for trees with heights above $1.30 \mathrm{~m}$; (a) $\leq 1$ (b) 1.01-10 (c) 10.01-20 (d) 20.01-30 (e) 30.01- 40 (f) 40.0150 (g) 50.01-60 (h) 60.01-70 (i) 70.01-80 (j) 80.1-90 (k) 90.01-100 and (l) $>100$. Tree volumes were not calculated as most of Acacia trees were multi-stemmed with different heights; thus impossible to measure height for each stem. Tree frequencies were presented in height class distribution and mean frequencies were compared accordingly. Regeneration potential and coppices for $A$. tortilis and $A$. kirkii were tabulated and the differences of their mean frequencies tested using ANOVA. Frequencies of regeneration potential between the two dominant Acacia species were tested with dead trees found in transects for any relationship. Data on trees with coppices were not subjected to statistical test due to their low numbers.

\section{Results and Discussion \\ Acacia Species}

A total of eight out of seventeen Acacia species previously recorded by Bjørstad (1976), were encountered in the sampled area. The species include Acacia tortilis (Forsk) Hayne, A. kirkii Oliv (Brenan), A. senegal (Willd) Brenan, A. mellifera (Vahal) Benth, A. tanganyikensis Brenan, A. robusta (Burch) Brenan, A. nilotica Willd and one Acacia species that could not be identified because pods, flowers and leaves were not available. The most common species in the sampled area were Acacia tortilis with 4,131 individual trees $(89.4 \%)$, mean density of $69 \pm 6$ trees/ha, followed by Acacia kirkii with 395 trees (8.5 $\%)$ and mean density of $7 \pm 1$ trees/ha. The remaining Acacia species accounted for only 94 
trees $(2.1 \%)$ and mean density of 2 trees/ha. Therefore, A. tortilis and A. kirkii were selected basing on abundance, mean densities and distribution (A. tortilis was recorded in 249 subplots while $A$. kirkii occurred in 66 sub-plots of 600 sampled sub-plots).

\section{Effect of Browsing on Acacia Trees}

Elephant damage on Acacia was assessed from 1,007 recruitment and mature trees. There were no clear signs of elephant browsing on regeneration class (trees $<1 \mathrm{~m}$ ) as they were probably uprooted. About $79.3 \%$ of Acacia trees were not browsed or slightly browsed, $8.9 \%$ had $1 / 4$ of the crown browsed, $3.7 \%$ with $1 / 2$ of crown browsed, $2.3 \%$ had $3 / 4$ of the crown browsed, $5.1 \%$ with whole crown browsed and $0.7 \%$ of all trees uprooted/pushed (Fig. 3). The last three browsing categories i.e. $3 / 4$ of crown, whole crown browsed and uprooted/pushed that were considered to be severely damaged accounted for only $8.0 \%$ of sampled trees. These categories are considered to be severe because the trees nearly died.

Thus, elephant browsing does not pose a big threat to Acacia trees, as previously found (Nahonyo, 1996). However, A. tortilis was the most browsed tree species $(24.9 \%)$ in the Acacia zone. Low utilization of woody vegetation was probably attributed to low elephant population estimated at 6,228 \pm 1544 in 2006 (TAWIRI, 2009). In addition, RNP is naturally protected due to the inclusion of Usangu Game Reserve to extend about 20,000 $\mathrm{km}^{2}$ since 2008 .

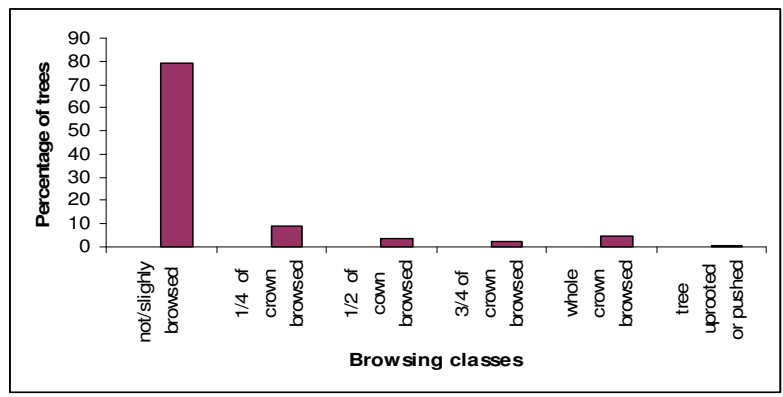

Figure 3: Browsing classes for all Acacia trees in the study area in RNP

This expansion could have reduced the intensity of elephant activities around permanent water points including GRR because elephants disperse in bigger area. The increased survival of $A$. drepanolobium was noted after expansion of the reserve and opening of corridors probably due to reduced browsing pressure. Yearly drying up of the GRR could have influenced elephant browsing pressure (Van Aarde, 2008). Virtually the river stops flowing during dry period leading to variations in utilization intensities of Acacia trees in the areas adjacent to GRR with consequent impacts near water pools.

Observations from planted Acacia trees near the office and staff houses outside the study area indicated severe damage with suppressed regeneration and slow recovery in Msembe area due to elephant browsing pressure (Nahonyo, 1996). Vegetation study (Bjørstad, 1976) in RNP suggests that A. tanganyikensis woodland was once well established in Msembe area. But, observations showed the presence of A. tortilis regeneration potential replacing $A$. tanganyikensis. Interestingly, elephant dung boli with plastic bags were observed around Msembe area, an indication that elephants could also feed from refuse pits. This might influence elephant ranging patterns in the area leading to increased browsing pressure on planted Acacia trees and other woody plants around the offices and staff quarters.

\section{Effects of Elephant Browsing on Selected Acacia trees}

Elephant browsing intensity on A. tortilis show that $80.9 \%$ of trees were not or slightly browsed, $4.3 \%$ severely browsed and 1.0\% uprooted/pushed. A. kirkii had $75.8 \%$ of trees not or slightly browsed and $12.1 \%$ with whole crown browsed, while all severely browsed $A$. kirkii trees accounted for $16.1 \%$ (see Fig.4). The difference in browsing intensity between $A$. tortilis and $A$. kirkii was not significant $\left(\mathrm{F}_{1,10}=\right.$ $0.6, \mathrm{p}>0.05)$, except for browsing classes $\left(\mathrm{F}_{5,6}\right.$ $=7.54, \mathrm{p}<0.05)$. This perhaps was attributed to low number of recorded $A$. tortilis (624) and $A$. kirkii (330) trees (above $1 \mathrm{~m}$ ) although the whole crown of the latter was relatively more severely browsed compared to the former. The relatively high proportion of severely damaged A. kirkii trees $(16.1 \%)$ might be attributed to easy access to individual clustered trees that grows in seasonally flooded areas. Almost all encountered $A$. kirkii trees were multi-stemmed shrub branching at the base (Dharani, 2006). Elephant aggregation in clustered Acacia trees supports 'optimal foraging theory' in that herbivores tend to browse more on resource rich areas (Wahungu, 2011). Gadd (2002), made a similar observation on marula trees Sclerocarya birrea in South Africa. In addition, localized browsing pressure coupled with low regeneration potential could eliminate $A$. kirkii in some areas if elephants develop preference to these trees. 


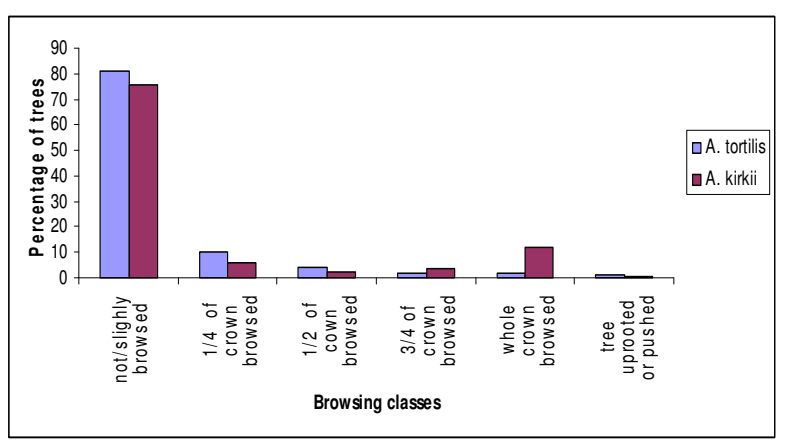

Figure 4: A. tortilis and A. kirkii browsing classes in the study area in RNP

\section{Debarking}

A total of 4,560 stems (i.e. 1626 of $A$. tortilis and 2,934 of A. kirkii) were assessed for debarking. Individual stems were examined since only one or few stems in multi-stemmed trees were debarked by elephants. About 98.2 $\%$ of all stems were not debarked and less than $0.5 \%$ of the stems were severely damaged indicating a low level of elephant damage (see Table 1). On the other hand, A. tortilis had 1.2 $\%$ of its stems severely debarked compared to only $0.03 \%$ of $A$. kirkii. In addition, there was no sign of any stem that was ring barked and the difference in debarking between the two species was not statistically significant $\left(\mathrm{F}_{1,6}=\right.$ $0.157, p>0.05)$, perhaps due to low numbers of debarked stems enumerated in both species.

Table 1: Debarking classes for A. tortilis and A. kirkii stems in in RNP

\begin{tabular}{lll}
\hline Debarking classes & & Number of stems \\
\hline & A. tortilis & A. kirkii \\
Not debarked & 1563 & 2920 \\
$<1 / 2$ debarked & 42 & 13 \\
$1 / 2-3 / 4$ debarked & 15 & 1 \\
Completely debarked & 6 & 0 \\
\hline
\end{tabular}

Relatively, there were more damaged $A$. tortilis stems $(1.2 \%)$ compared to A. kirkii $(0.03 \%)$ probably due to more single stemmed trees with greater mean diameter $(17.9 \pm 0.7 \mathrm{~cm})$ compared to multi-stemmed $A$. kirkii trees with lower mean diameter $(4.1 \pm 0.12 \mathrm{~cm})$. Multi-stem growth protect trees from ring barking and smaller branches provide little amount of forage than larger stems (Wanderi, 2007). Elephants preferentially debark $A$. tortilis than A. kirkii more frequently (Chira and Kinyamario 2009). A study in Samburu and Buffalo Springs National Reserves in Kenya, showed elephant debarking preference for A. elatior to A. tortilis due to higher levels of sodium, potassium, calcium and zinc. In addition, A. elatior and $A$. tortilis trees with diameters ranging from 25.5 to $51 \mathrm{~cm}$ were the most debarked, in a similar fashion to these results (Figure 5)

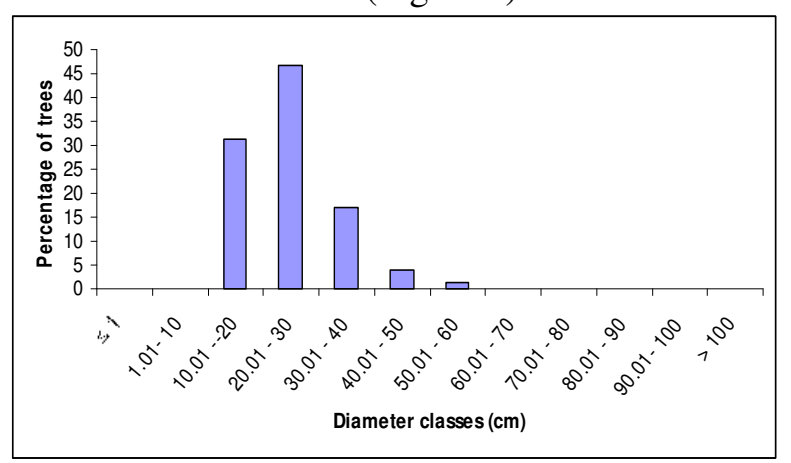

Figure 5: Debarking by diameter classes of combined A. tortilis and A. kirkii in RNP
These observations indicate low damage resulting from elephant browsing and debarking as well as insignificant difference in damage between A. tortilis and A. kirkii. Nonetheless, patchy and clumped distribution and multi-stem growth form make $A$. kirkii more vulnerable than A. tortilis which are affected mostly through debarking and uprooting/pushing.

\section{Acacia Tree Densities along Transects}

Statistical test between distance from the river along transects and tree densities indicated a weak relationship for $A$. tortilis $(\mathrm{R}=0.06)$, but a strong relationship for A. kirkii tree densities $(\mathrm{R}=0.7)$. There was a weak relationship between the distance from river for A. tortilis ( $\mathrm{R}=0.3)$ and for A. kirkii $(\mathrm{R}=0.1)$ (see Table 2). This trend suggests that regeneration potential of both species is influenced by factors other than distance from the river. This variation cannot be attributed to elephant feeding only since the transect length $(1 \mathrm{~km})$ was too short, given low level of browsing and debarking. 
Table 2: Relationship between distance from the river and Acacia trees in RNP

\begin{tabular}{llll}
\hline & $\mathrm{R}$ & $\mathrm{R}^{2}$ & Equations \\
\hline Trees $<1 \mathrm{~m}$ (Regeneration potential) & & & \\
A. tortilis & 0.349 & 0.122 & $\mathrm{Y}=0.315 \mathrm{x}+41.9315$ \\
A. kirkii trees $>1 \mathrm{~m}$ & 0.099 & 0.010 & $\mathrm{Y}=0.0004 \mathrm{x}+0.8718$ \\
A. tortilis & 0.063 & 0.004 & $\mathrm{Y}=-0.0006 \mathrm{x}+10.7368$ \\
A. kirkii & 0.746 & 0.557 & $\mathrm{Y}=0.0086 \mathrm{x}+0.9789$ \\
\hline
\end{tabular}

The observed relationship was probably an influence of soil factor because areas close to river banks are well drained and seasonal flooding is uncommon. Generally, more $A$. kirkii trees were recorded in areas with seasonal shallow water channels and temporary flooding. In contrast, A. tortilis is adapted to a wide range of soil types (except seasonally waterlogged) hence widely distributed in the study area. There were fewer A. tortilis in areas with dense bush of Cordia gharaf, Maytenus and Vernonia species near the river bank and on ridges with Combretum trees, where most transects ended. A. tortilis being a shade intolerant species could not grow in thick bush, while in Combretum area; fire could have played a role in limiting regeneration and growth in addition to soils.

\section{Population Structure and Composition}

Basal area, tree heights and tree diameters were used to classify Acacia trees in different sizes since it was impossible to age them using other methods. Mean diameters for A. tortilis and A. kirkii were $17.9 \pm 0.7$ and $4.1 \pm 0.2 \mathrm{~cm}$ respectively with the overall mean diameter of $12.9 \pm 0.5 \mathrm{~cm}$. There was a significant statistical difference between $A$. tortilis and A. kirkii in basal areas $\left(\mathrm{F}_{1,22}=11.8, \mathrm{p}<0.05\right)$ and no significant difference was observed between diameter classes $\left(\mathrm{F}_{11}, 12, \mathrm{p}>0.05\right)$. Most $A$. kirkii trees were multi-stemmed shrubs with smaller stem diameters, while A. tortilis had relatively fewer stems but with larger diameters. Distribution of basal area by diameter classes represented population structure of A. tortilis and A. kirkii for trees above $1.30 \mathrm{~m}$ height (Fig. 5). All A. tortilis had stems distributed in all diameter classes with $20.01-30 \mathrm{~cm}$ and $30.01-40 \mathrm{~cm}$ accounting for a large basal area and diameter classes presenting decreasing number of bigger trees. The structure of the curve is not a negative exponential or inverted J-curve shape. Negative exponential curve or inverse $\mathrm{J}$-shape curve indicate a healthy regeneration of a woodland or forest. A. kirkii chart is also different from an inverted J-shaped curve, with a high basal area in one diameter class $(1.01-10 \mathrm{~cm})$, lower in 20.01-30, lowest in $40.01-40 \mathrm{~cm}$ and none in the remaining classes (Figure 6).

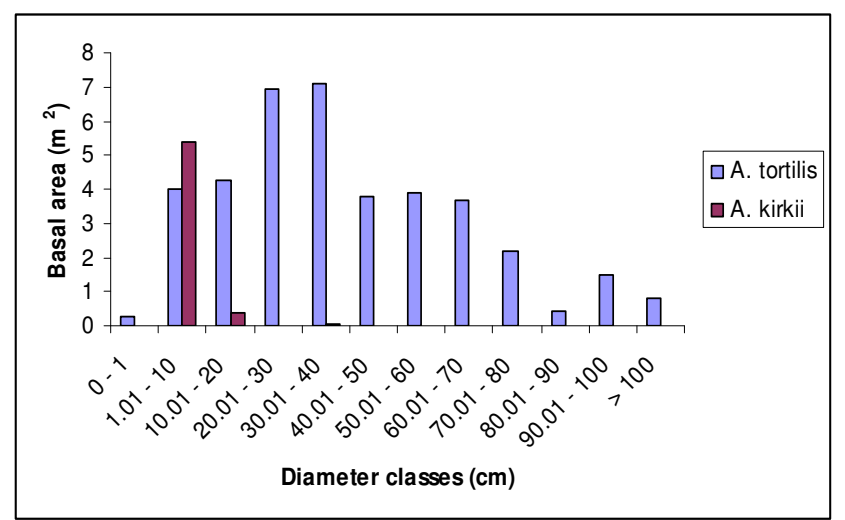

Figure 6: Basal area $\left(\mathrm{m}^{2}\right)$ by diameter classes of A. tortilis and A. kirkii in in RNP

The mean tree height for $A$. tortilis and $A$. kirkii was $7.4 \pm 0.2 \mathrm{~m}$ and $4.5 \pm 0.2 \mathrm{~m}$, respectively. The tree height class distribution curve for $A$. tortilis exhibit approximately a negative exponential curve (inverted J-curve), with a greater number of individual trees $(84.6 \%)$ in regeneration potential (trees $<1 \mathrm{~m}$ ) followed by mature trees (trees $>3 \mathrm{~m})(11.7 \%)$ and the recruitment potential (trees $1-3 \mathrm{~m}$ ) with a lowest number of trees $(3.7 \%)$. On the other hand, $A$. kirkii trees had lower regeneration potential $(16.6 \%), 43.9 \%$ in recruitment potential and $39.5 \%$ in mature class. The diameter class distribution for $A$. tortilis suggests interrupted regeneration and recruitments continuity at different stages of tree growth resulting into a bell shaped curve (Figure 7).

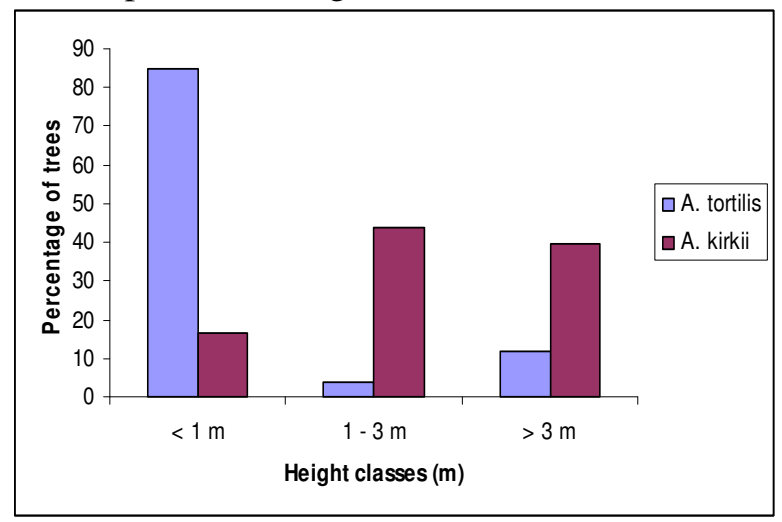

Figure 7: Tree height class distribution of $A$. tortilis and A. kirkii in RNP

The recruitment gaps could be a result of disturbances through browsing, fires and 
prolonged drought which might have killed young seedlings or retarded their growth through recruitment potential. For A. kirkii, the basal area and diameter distribution curve reflects the multi-stemmed growth form of the species with many smaller stems and few single stemmed trees above $30 \mathrm{~cm}$ in diameter. This suggests that, the use of basal area and diameter alone in determining population structure of multi-stemmed trees species could lead to erroneous conclusion.

The low basal area in the $0-1 \mathrm{~cm}$ diameter class could indicate low recruitment from the regeneration potential, in addition to smaller diameters of trees in this class. This is supported by the large proportion (94.1\%) of $A$. tortilis and A. kirkii seedlings with height below $0.3 \mathrm{~m}$ and low number of trees with a height between 1 and $3 \mathrm{~m}$, suggesting a suppressed growth of seedlings into recruitment potential class. Fire and browsing could as well have affected the recruitment potential since the class falls in the $1-3 \mathrm{~m}$ height, a preferred browsing range by elephant (Mtui and Owen-Smith, 2006). Thus, elephant browsing could have killed or suppressed recruitment of trees into mature class. Moreover, A. kirkii tree height indicate low number of individual trees in regeneration potential, highest in recruitment potential followed by mature trees class. This distribution suggests poor potential for future trees recruitment and consequently into mature trees.

\section{Growth Responses from Acacia Species Coppices}

A total of 23 out of 1,007 trees resprouted after elephant damage. Most of the resprouted trees were A. tortilis (87.0\%), three other combined Acacia species (13.0\%), and none of A. kirkii had coppices. The low proportion of Acacia trees with coppices was a result of drought since the study was conducted at the end of the prolonged dry season. Furthermore, genotypic differences between species (Sennerby-Forsse and Zsuffa, 1993) could be associated with absence of $A$. kirkii trees with coppices after damage by elephants. A. kirkii is adapted to seasonally flooded soils, while $A$. tortilis grow in a wide range of soil types with deeper roots to access water. Many Acacia species have little or no coppicing ability when mature hence some of the sampled trees could not resprout after elephant damage. Moreover, Acacia trees may need more than two seasons to coppice. Other observation (Chira and Kinyamario 2009) suggests that five woody plant species (Acacia ataxacantha, A. brevispica, Grewia bicolor, G. tembensis and $G$. virosa) coppiced in a fairly short time after were browsed by elephants.

\section{Regeneration Potential}

A total of 3,613 trees $(<1 \mathrm{~m}$ and mean height of $0.25 \pm 0.003 \mathrm{~m}$ ) were enumerated. $A$. tortilis formed a large proportion $(97.1 \%)$ of total regeneration potential with only $1.8 \% \mathrm{~A}$. kirkii. There was a significant difference in regeneration potential between $A$. tortilis and $A$. kirkii, $\left(\mathrm{F}_{1,58}=41.36, \mathrm{p}<0.05\right)$. Acacia species are known to have a capacity to regenerate rapidly from seedlings (Western and Maitumo, 2004) but their survival is dependent on soil, fire, herbivores and climatic variations (Wahungu, 2011; Stave et al., 2006). Thus, adaptation to different soil types might cause a huge difference in regeneration potential. $A$. tortilis grows in a wide range of soils while $A$. kirkii is restricted to seasonally flooded areas (Dharani, 2006). Seed dispersal by elephant and other agents is likely to favour $A$. tortilis than $A$. kirkii due to its versatility to different soil types.

Most of trees $<1 \mathrm{~m}(94.1 \%)$ were under $0.3 \mathrm{~m}$ height, $3.7 \%$ between $0.3-0.5 \mathrm{~m}$, while only $2.2 \%$ between $0.5-1 \mathrm{~m}$, resprouted after damage by fire and partial browsing. The higher proportions of trees $<0.3 \mathrm{~m}$ height suggest probable annual suppression of seedling growth. According to Barnes (1985), smaller browsers such as impala and kudu reduced Acacia erioloba seedlings mean height but could not reverse growth to ground level, whereas fire and elephant reversed the growth of seedlings to ground level. Pellew (1983) affirm that elephants in Serengeti National Park ignored trees $<1 \mathrm{~m}$ height whereas in HluhluweImfolozi Park elephants had little effect to smaller trees $<1 \mathrm{~m}$ (Boundja andMidgley 2007). Elsewhere, elephants frequently browsed on seedlings $<1 \mathrm{~m}$ (Jachmann and Bell, 1985) but it's difficult to know if elephants fed on or ignored regenerating trees in RNP. Therefore, fire and small browsers were the likely factors influencing growth of Acacia seedlings in the study area apart from climatic variations.

Regeneration potential of dead A. tortilis and $A$. kirkii trees killed as a result of elephant browsing did not show a strong relationship ( $A$. tortilis, $\mathrm{R}=0.16$ and $A$. kirkii, $\mathrm{R}=0.01$ ). This indicates that the regeneration potential was probably not influenced by elephants browsing pressure. Besides, A. tortilis seedlings were observed in open grassland where no mature trees were killed by elephants. In some transects, trees killed by elephants were 
enumerated without any single Acacia seedlings. This could be an indication that reestablishment by regeneration in areas where Acacia trees are killed take sometimes. Thus, death of mature trees would be expected to allow germination and regeneration of seedlings. This study confirmed that $A$. nilotica seedlings grow under their mature parent trees or $A$. tortilis mature tree crowns.

\section{Conclusion and Recommendation}

The observed significant difference in regeneration potential was not detected in debarking and browsing between the two dominant Acacia species, A. tortilis and A. kirkii. Statistical tests on coppicing proved difficult due to the low number of $A$. tortilis trees that sprouted and none of A. kirkii trees had coppices. The effects of elephant browsing and responses after damage were apparent, but not statistically significant. This led to failure to reject the hypothesis that, dominant Acacia species are equally damaged and respond equally to elephant damage.

The low level of elephant damage indicate less threat to Acacia species with the exception of $A$. kirkii, that was locally affected due to patchy and clumped distribution. The variation in Acacia trees densities with increasing distance along transects was probably influenced by soil, vegetation cover and fire, and not elephant browsing. A. tortilis showed a high potential for future recruitment compared to A. kirkii. This is indicated by high A. tortilis regeneration potential. Fire and small browsers could likely suppress regeneration potential whereas variability in soil and climate could determine both coppicing and regeneration of Acacia trees. Fire as a management tool can suppress or enhance recruitment of A. tortilis depending on the purpose of management intervention. The area between Msembe and Lunda could develop into A.tortilis bush/woodland if factors that suppress recruitment potential are identified and controlled appropriately. If an area is left into Acacia bush/woodland it could adversely affect important species of mammals such as Grants gazelle Nanger granti and cheetah Acynonyx jubatus that prefer open grassland.

\section{Management Implication}

Elephant utilization on Acacia trees is likely to vary along the Great Ruaha River depending on the availability of surface water in dry seasons; hence it is important to conduct a study on effects of elephant browsing on vegetation around permanent water points. It is therefore recommended that:

A study on the impact of browsing by other animal species and of Acacia species regeneration potential need to be done across seasons to establish the actual causes for suppressed tree regeneration, in addition to the influence of human activities on elephants and other browsers around Msembe.

- Another study should focus on the Acacia vegetation zone to get a better understanding of $A$. kirkii regeneration and coppicing as a response after damage.

- A study on effects of fire on regeneration of Acacia trees to be conducted to ascertain the use of fire as a management tool.

- Moreover, close monitoring of changes taking place in vegetation in area should be done continuously to predict the likely future vegetation cover and how the changes would affect the associated animal species in two distinct seasons.

\section{Acknowledgement}

We thank TANAPA's management for financial support and for allowing us to conduct studies in RNP. We also thank Prof. R.P.C. Temu and Prof. S. Hassan for commenting on the draft manuscript.

\section{References}

Barnes, R.F.W. (1982). Elephant feeding behaviour in Ruaha National Park, Tanzania. African Journal of Ecology 20(2):123-136

Barnes, R.F.W. (1985). Woodland changes in Ruaha National Park Tanzania between 1976 and 1982. African Journal of Ecology 23(4):215-221.

Blake, S., Deem, S.L., Mossimbo, E., Maisels, F. and Walsh, P. (2009). Forest Elephants: Tree Planters of the Congo. [http://www.Aginternetwork.net/whaleco mmonline library.wiley.com] site visited on $18 / 7 / 2011$.

Bjørstad, A. (1976). Vegetation of Ruaha National Park, Tanzania: I. Annotated Checklist of the Plant Species. Serengeti Research Institute, SRI PBL, NO.215, OSLO 61pp.

Boundja, R.P. and Midgley, J.J. (2007). Patterns of elephant impacts in the Hluhluwe-Imfolozi Park, KwaZulu-Natal, South Africa. [http://www.3interscience.wiley. com] site visited on $25 / 2 / 2010$ 
Chira, R.M. and Kinyamario, J.I. (2009). Growth response of woody species to elephant foraging in Mwea National Reserve, Kenya. [http://onlinelibrary.wiley.com] site visited on $29 / 08 / 2010$.

Dino, M. (2010). Not all ants are equal: Obligate Acacia ants provide different levels of protection against mega herbivores.[http://www.aginternetwork.net /whale commonlinelibrary.wiley.com] site visited on 21/3/2011

Dharani, N. (2006). Field Guide to Acacias of East Africa. Stuik Publishers, Cape Town South Africa. 200pp.

Fornara, D.A. and du Toit, J.T. (2007). Browsing lawn? Response of Acacia nigrecens to ungulate browsing in an African savanna. [http: eprints.ulster.ac.uk] site visited on 29/08/2010Beetje, H. J. 1994. Kenya Trees Shrubs and Lianas. National Museum of Kenya, Nairobi. 722pp.

Gadd, M.E. (2002). Impact of elephants on marula tree Sclerocarya birrea. [http://www.3interscience.wiley.com ] site visited on 25/2/2010.

Hema, E.M., Barnes, R.F.W. and Guenda, W. (2010). Distribution of savanna elephants (Loxodonta Africana Blumenbach 1797) within Nazinga Game Ranch. [http://www.Aginternetwork.net/whaleco mmonlinelibrary.wiley.com] site visited on $30 / 03 / 2011$

Jachmann, H. and Bell, R.H.V. (1985). Utilization by elephants of Brachystegia woodlands of Kasungu National Park, Malawi. African Journal of Ecology 23: 245- 258.

Kabigumila, J. (1993). Feeding habits of elephant in Ngorongoro Crater, Tanzania. African Journal of Ecology 31 (2):156-164

Ihwagi, F.W., Vollrath, F., Chira, R.M., Douglas-Hamilton, I. and Kironchi, G. (2009). Impact of elephants, Loxodonta Africana, on woody vegetation through selective debarking in Samburu and Buffalo Springs National Reserves, Kenya. [http://www.3interscience.wiley.com ] site visited on 25/2/2010.

Kerley, G.H.I., Landman, M., Kruger, L., Owen-Smith, N. (2008). Effects of elephants on ecosystems. Elephant Management: A Scientific Management of South Africa. In: Scholes, R.J. and Mennell, K.G.(Eds.). Witwatersrand University Press, Johannesburg. [http://elephantassessment.co.za/files] site visited on 23/03/2010

Lewis, D.M. (1991). Observation of tree growth, woodland structure and elephant damage on Colphospermum mopane in Luangwa Valley, Zambia. [http://www.3inter science.wiley.com] site visited on 25/2/2010.

Majid, K., Gilbert, B.I. and Jeremiah, L.S. (2010). Role of Acacia and Erythryna trees in forest regeneration by vertebrate seed dispersers in Kibale National Park, Uganda.

[http://www.Aginternetwork.net/whaleco mmonlinelibrary.wiley.com] site visited on $30 / 03 / 2011$.

Mapping and Survey Division (1972). Topographic sheets number 196/3 (Nyalengi), 213/2 (Ngarija) and 214/1 (Idodi). Dar es Salaam.

Mtui, D. and Owen-Smith, N. (2006). Impact of elephants (Loxodonta africana) on woody plants in Malolotja Nature Reserve, Swaziland. [http://www.3interscience. wiley.com] site visited on 25/2/2010

Mwalyosi R.B.B. (1990). Dynamic ecology of Acacia tortilis woodland in Lake Manyara National Park, Tanzania. African Journal of Ecology 28 (3):189-199.

Nahonyo, C.L. (1996). Impact of elephant browsing on vegetation in Ruaha National Park, Tanzania. Thesis for award of MSc Degree at the University of Dar es Salaam, Tanzania. 176pp.

Ngene, S.M., Gils H.V., van Wieren, S.E., Rasmussen, H., Skidmore, A.K. Prins, H. H.T., Toxopeus A.G., Omondi, P. and Douglas-Hamilton, I. (2009). Ranging pattern of elephants in Marsabit protected area, Kenya: the use of satellite linked GPS collars. [http://www.3interscience.wiley.com] site visited on $25 / 2 / 2010$.

Okula, J.P. and Sise, W.R. (1986). Effects of elephant browsing on Acacia seyal in Waza National Park, Cameroon. African Journal of Ecology 24 (1):1-6.

Stave J., Oba, G., Nordal, I. and Stenseth, N.C. (2006). Seedling establishment of Acacia tortilis and Hyphaene compressa in the Turkwel riverine forest, Kenya. [http://www.Aginternetwork.net/whaleco mmonlinelibrary.wiley.com] site visited on 31/03/2011.

Sennerby-Forsse, L. and Zsuffa, L (1993). Bud structure and resprouting in coppiced stools of Salix viminalis S. eriocephala 
and $\quad S . \quad$ amygdaloides. [http:www.springerlink. com] site visited on $26 / 04 / 2011$.

Tanzania National Parks (TANAPA) (2008). Ruaha National Park General Management Plan (2008-2017), Arusha. $154 \mathrm{pp}$

Tanzania Wildlife Research Institute (2009). Aerial Census in the Ruaha-Rungwa Ecosystem, Dry season, 2006. Arusha. $56 \mathrm{pp}$.

Vesey-Fitzgerald, D. (1973). Browse production and utilization in Tarangire National Park. East African Wildlife Journal 11:291-305.

Wahungu, G.M., Mureu, L.K., Kimuyu, D.M., Birkett, A., Macharia, P.G. and Burton J. (2011). Survival, recruitment and dynamics of Acacia drepanolobium Sjøstedt seedlings at Olpejeta Conservancy, Kenya, between 1999 and 2009.

[http://www.Aginternetwork.net/whaleco mmonlinelibrary.wiley.com] site visited on 10/02/2011.
Wanderi, I.F. (2007). Forage quality and bark utilization by the African elephant (Loxodonta africana) in Samburu and Buffalo Springs National Reserves, Kenya. [http://www.savetheelephant.org] site visited on 10/2/2011

White, L. and Edwards, A. (2000). Vegetation inventory and description. Conservation Research in the African Rain Forest: A Technical Hand Book. In: White, L. and Edwards, A. (Eds.). The Wildlife Conservation Society, New York, pp. $115-151$.

Western, D and Maitumo, D. (2004) Woodland Loss and Restoration in a Savanna Park: A 20-year Experiment. African Journal of Ecology, 42, 111-121.

Young, T.P. and Augustine. D.J. (2007). Intraspecific variation in reproduction response of Acacia species to protection from large mammalian herbivores. [http://onlinelibrary.com] site visited on 28/08/2010. 